\title{
KNOWLEDGE AND PERCEPTION TOWARDS SUPPLEMENTARY IMMUNIZATION ACTIVITIES (SIA) AMONG MOTHERS IN CHERAS, KUALA LUMPUR
}

\author{
Mohd Rohaizat Hassan ${ }^{1}$, Muhammad Afham Azman ${ }^{1}$, Chong Li Yong ${ }^{1}$, Tengku Mardhiah Tengku Nazmi ${ }^{1}$, \\ Nurul Najwa Abdul Rashid ${ }^{1}$, Wan Nur Alya Shaqeera Wan Azmi ${ }^{1}$, Nazarudin Safian ${ }^{1}$, Noriah Hajib ${ }^{2}$, Al- \\ abed Ali Ahmed Al-abed ${ }^{3}$ and Hasanain Faisal Ghazi ${ }^{4}$ \\ ${ }^{1}$ Department of Community Health, Faculty of Medicine, University Kebangsaan Malaysia. \\ ${ }^{2}$ Cheras District Health Office, Kuala Lumpur. \\ ${ }^{3}$ Department of Community Medicine, Faculty of Medicine, Lincoln University College, Petaling Jaya, Selangor, \\ Malaysia. \\ ${ }^{4}$ Community Medicine Unit, International Medical School, Management and Science University, Selangor, Malaysia.
}

Corresponding author: Hasanain Faisal Ghazi

Email: dr.hasanainhabasha@gmail.com

\begin{abstract}
Among the main reasons for re-emergence of vaccine preventable diseases were missed or incomplete immunization schedule. The supplementary immunization activity $(S I A)$ is an important intervention done to provide complete immunization coverage among those children. Better outcome came along with good knowledge and perception on the program. Thus, this study aims to assess the level of knowledge and perception of the mothers towards SIA program. A cross-sectional study was conducted among mothers with children $\leq 15$ years old in Cheras, Kuala Lumpur. Data was collected by interview using the guided questionnaire consists of four sections to assess the socio demographic, socio economic, knowledge and perception regarding SIA. The questionnaire was validated for internal consistency with Cronbach's alpha 0.461 for knowledge and 0.729 for perception. A total of 105 respondents with the median age of 33 years (IQR: 28-38) with majority of them are Malays (82.9\%), Muslim (83.8\%), married (97.1\%) and (57.1\%) with $1-2$ child in the family. Half of them were from low income family (46.7\%) and had secondary education level (54.3\%) and were housewives (47.6\%). One third of the respondents (33\%) never heard about SIA before. Overall had poor knowledge (82.9\%) and perception (95.2\%) towards SIA. There is a significant association between the level of knowledge on SIA with household income $\left(x^{\wedge} 2=7.746, p=0.019\right)$ and occupation $\left(x^{\wedge} 2=6.457, p<0.05\right)$. However, there was no significant association between the socio demographic and socio-economic factors and perception towards SIA. In conclusion, the knowledge and perception among mothers on SIA are still poor. More intensive health educations may be useful to be incorporated within the program implementation to increase the community understanding and perception towards SIA in the future.
\end{abstract}

Keywords: knowledge, perception, SIA, supplementary immunization activity, Kuala Lumpur

\section{INTRODUCTION}

Supplementary Immunisation Activities (SIA), also referred as mass-immunisation campaigns, is an effective strategy for delivering vaccination to children otherwise missed by routine services or to older susceptible individuals who are not among the age groups targeted by the routine expanded program on immunization (EPI) services. ${ }^{1}$ SIA, according to World Health Organisation (WHO), can also be employed as a medium to advocate the public regarding immunisation practices, the effect of vaccination have in building the national capacity and national health as a whole and as a platform to provide other health interventions and services. ${ }^{2}$

SIA has been proven to work in many countries for instance, measles in China and polio in Nigeria and India. ${ }^{3-5}$ SIA was also implemented during an outbreak in some European countries in the 1990s, re-enforcing the ability of this programme to reduce the incidence rate of vaccine-preventable diseases. ${ }^{6}$ WHO states that global immunisation prevents two to three million deaths every year with its current estimated immunisation coverage of more than $85 \% .{ }^{7}$ Malaysia introduced its own immunisation programme in 1950s which is available for all national citizens. It is long established that Malaysia has good national immunisation coverage, for example, the country reported more than $95 \%$ immunisation coverage in the year 2000, 2005 and in 2012. ${ }^{7}$

SIA is expected to play its role to reduce the disease occurrence by providing complete immunisation especially to those who might miss the scheduled immunisation schedule in the past, to the extent of providing and sustaining the herd immunity in the population. SIA was also successfully implemented by Malaysia in 2004 for measles, as recorded by the WHO and it results in immunization coverage in 2004 to reach up to $100 \%$, resulting in plummeting measles cases reported in 2005 which dropped to one tenth from previous year. ${ }^{7}$ Despite having good routine immunisation coverage through SIA implementation in Malaysia, there is still emergence of outbreak of vaccine preventable diseases. Thus, the provider's factors might not 
be the only factors in determining the successfulness of the programme. Facts on how much the mothers understood and perceived especially on the SIA programme is still under studied. This study aims to assess knowledge and perception of mothers towards SIA.

\section{MATERIALS AND METHODS}

A cross-sectional survey was conducted from 4th to 20th September 2017 in Cheras, Kuala Lumpur. A total of 105 mothers were interviewed. Malaysian mothers more than 18 years old with children 15 years old and below whom are fluent in spoken Malay language or English were recruited in the study. Exclusion criteria include resident foreigners and mothers from vulnerable group such as single parent. Convenient sampling was used, and data was collected by face-to-face interviews by trained interviewers in either Malay language or English using standardized questionnaires. Eligible mother was informed of the study objectives and informed consent was obtained before the interview started.

The questionnaires were self-developed and validated through a pilot study using different samples from the current study with the Cronbach's Alpha of alpha 0.461 for knowledge and 0.729 for perception. The questionnaires were divided into four sections. The first and second section consists of socio demographic and socio-economic details of the participants respectively. The third and fourth section have equal amount of positive and negative questions placed in a non-consecutive way. A total of 10 question in third section assess the knowledge of the participants with 3 possible answers (Yes, No or Not sure). A score of more than $50 \%$ is considered as good knowledge. The fourth section consists of 12 questions assessing the participant's perception using a Likert scale for each question. A score of more than $50 \%$ is considered as good perception.

The data was cleaned and analysed using Statistical Package for Social Science (SPSS) version 22.0. Descriptive statistical methods were used to describe the study population using frequencies, mean ( \pm sd) and median (IQR). Bivariate analysis was used to determine the differences. Difference in means were compared using student $t$ test, correlation analysis for 2 continuous data, and chi-square for the categorical data. Respective non-parametric analysis was used when the data normality were not satisfied.

\section{RESULTS}

A total of 105 respondents were collected in this study. Table 1 shows the distribution of socio demographic data and Table 2 shows the distribution of the socio-economic data of the respondents. The median age of the respondents was 33 (IQR: 29.5-39.0) years old. The majority of the respondents were Malays (82.9\%), followed by Indians (10.5\%) and Chinese (5.7\%). Islam (83.8\%) was the major affiliation of the respondents, followed by Hinduism (9.5\%), Buddhism (4.8), and Christian (1.9\%). Almost all of the respondents were married $(97.1 \%)$ and half of the respondents have 1 to 2 children (57.1\%) in the family. Most of them finished their education in the secondary $(54.3 \%)$ and tertiary $(42.9 \%)$ levels. About half of the respondents were housewives (47.6\%). Majority of the household income were in the low (46.7\%) and middle (41.9\%) class. The respondents heard information regarding SIA the most from clinic and hospitals (48.0\%); however, there were also a major proportion of them $(33.0 \%)$ never heard of SIA before.

Table 1: Socio demographic details of the respondents

\begin{tabular}{lc}
\hline Variables & Total, $\mathrm{N}=105$ \\
\hline Age (in years); median (IQR) & $33(29.50-39.00)$ \\
Race, n (\%) & \\
Malay & $87(82.9)$ \\
Chinese & $6(5.7)$ \\
Indian & $11(10.4)$ \\
Others & $1(1.0)$ \\
Religion, $\mathrm{n}(\%)$ & \\
Islam & $88(83.8)$ \\
Christian & $2(1.9)$ \\
Buddhism & $5(4.8)$ \\
Hinduism & $10(9.5)$ \\
Marital Status, $n(\%)$ & \\
Married & $102(97.1)$ \\
Divorced & $3(2.9)$ \\
Number of child, $\mathrm{n}(\%)$ & \\
1-2 & $60(57.1)$ \\
$3-5$ & $38(36.2)$ \\
$\geq 6$ & $7(6.7)$ \\
\hline
\end{tabular}


Table 3 demonstrated that most of the respondent found to have poor knowledge $(82.9 \%)$ and poor perception (95.2\%) regarding SIA. Chi-square test was done and the results in Table 4 demonstrated there was a statistically significant association between the household income $\left(\chi^{2}=8.202\right.$, $p=0.017$ ) and the level of knowledge of the respondents. There were also statistically significant association between the occupation $\left(\chi^{2}=6.308, p=0.043\right)$ and the level of knowledge. There was no significant association between other factors to the level of knowledge. However, all of the socio-demographic and socio economic factors showed no significant association to the level of perception of the respondents.

Table 2: Socio economic details of the respondents

\begin{tabular}{cc}
\hline Variables & Total, $\mathbf{N}=105$ \\
\hline Level of Education, $\mathrm{n}(\%)$ & $3(2.9)$ \\
Primary & $57(54.2)$ \\
Secondary & $45(42.9)$ \\
Tertiary & \\
Occupation, $\mathrm{n}(\%)$ & $23(21.9)$ \\
Professionals & $32(30.5)$ \\
Non-professionals & $50(47.6)$ \\
Housewife & \\
Household Income, n (\%) & $49(46.7)$ \\
<2500 & $44(41.9)$ \\
$2500-5600$ & $12(11.4)$ \\
\hline 5600 & \\
\hline
\end{tabular}

Table 3: Level of Knowledge and Perception

\begin{tabular}{cc}
\hline Variables & Total, $\mathrm{N}=105$ \\
\hline Level of Knowledge, $\mathrm{n}(\%)$ & $18(17.1)$ \\
Good & $87(82.9)$ \\
Poor & $5(4.8)$ \\
Level of Perception, $\mathrm{n}(\%)$ & $100(95.2)$ \\
Good & \\
Poor & \\
\hline
\end{tabular}

Table 4: The associations between level of knowledge and level of perception and respondents socio demographic and economic factors

\begin{tabular}{lcc}
\hline \multicolumn{1}{c}{ Factors } & $\begin{array}{c}\text { Level of Knowledge, } \\
\mathrm{z} \text {-value }(p \text {-value })\end{array}$ & $\begin{array}{c}\text { Level of Perception, } \\
\mathrm{z} \text {-value }(p \text {-value })\end{array}$ \\
\hline Age & $-1.894(0.058)$ & $-0.241(0.809)$ \\
\hline \multicolumn{1}{c}{ Factors } & $\begin{array}{c}\text { Level of knowledge, } \chi^{2} \\
(p \text {-value })\end{array}$ & $\begin{array}{c}\text { Level of perception, } \chi^{2} \\
(p \text {-value) }\end{array}$ \\
\hline Race & $5.014^{\mathrm{a}}(0.225)$ & $2.931^{\mathrm{a}}(0.414)$ \\
Religion & $2.440^{\mathrm{a}}(0.488)$ & $6.906^{\mathrm{a}}(0.076)$ \\
Marital status & $0.000^{\mathrm{b}}(0.982)$ & $0.000^{\mathrm{b}}(1.000)$ \\
Number of child & $2.210^{\mathrm{a}}(0.404)$ & $3.726^{\mathrm{a}}(0.123)$ \\
Level of education & $1.376^{\mathrm{a}}(0.462)$ & $1.601^{\mathrm{a}}(0.465)$ \\
Household income & $7.746^{\mathrm{a}}(0.019)^{*}$ & $4.278^{\mathrm{a}}(0.106)$ \\
Occupation & $6.457^{\mathrm{a}}(0.036)^{*}$ & $2.119^{\mathrm{a}}(0.426)$ \\
\hline
\end{tabular}

${ }^{\mathrm{a}}$ Fisher Exact Test, ${ }^{\mathrm{b}}$ Continuity Correction, ${ }^{*}$ significant $p<0.05$

\section{DISCUSSION}

Majority of the respondents had low knowledge and poor perception towards SIA despite the program being implemented one week prior to the study. These unsatisfactory findings illustrated the lack of concern and awareness of the mothers towards this issue and program. A study in Enugu, Nigeria found that their respondents had good knowledge regarding SIA which contraindicated to our finding. ${ }^{8}$ However, it was not surprising to see such results since one third of the respondents had never heard about SIA before. This could be contributed to their absence or lack of awareness during the duration in which the campaign was being done. Nonetheless, this is an important factor to be considered and intervened early as knowledge about immunization greatly influence immunization rate and in this case, SIA program. ${ }^{9}$ 
Figure 1 Percentages of respondent ever heard about SIA and its sources

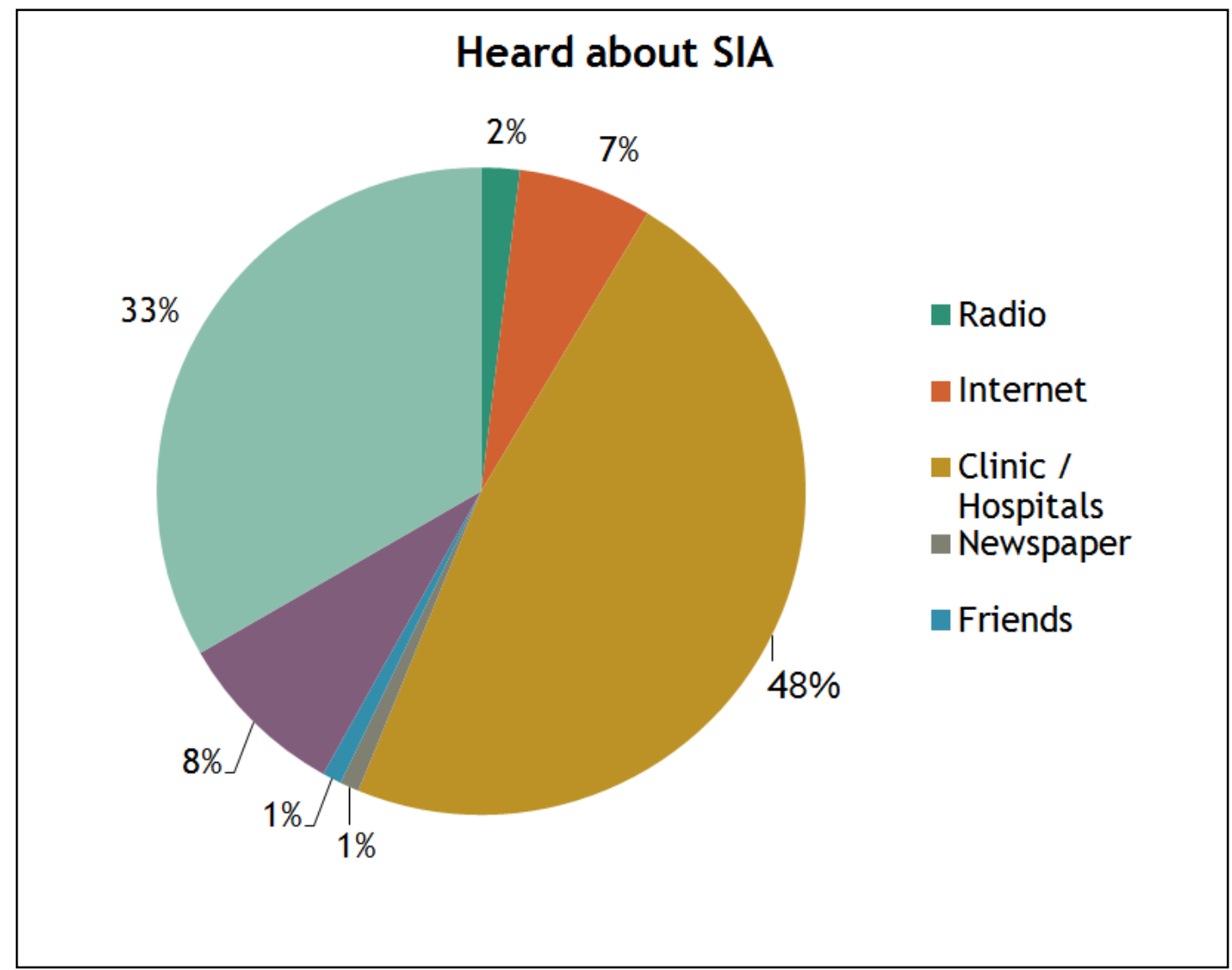

More than $90 \%$ of respondents had poor perception towards SIA which corresponded to a research done in Karachi regarding SIA for polio. ${ }^{10}$ It was reasoned as due to the doubts surrounding the vaccine especially the content in which it may contain non-halal ingredients, the need, the efficacy and the safety of the vaccine. Another study showed good perception towards vaccination and routine vaccination however, it was not the case for SIA, as demonstrated by a significant rate of refusal for SIA. ${ }^{8}$ The mothers preferred going to hospitals for full examination of the child. The vaccine provider during SIA was also said to be less trustworthy as compared to the hospital and some felt there was no need for extra vaccine doses.

Regardless of the maternal age, the marital status, the socio-cultural factors as well as the number of child, there were no significant association with the level of knowledge and perception towards SIA. This might be contributed by the widely accessible services with widespread healthcare facilities in Malaysia available for every Malaysians. A study about vaccination in Sabah and a Malaysian nation-wide communitybased survey also found that there were no significant associations between maternal age and marital status with vaccination. ${ }^{11,12}$ The same study also found that race had no significant association with vaccination. ${ }^{12}$ Religious denomination was found not significantly associated with rejection of immunization during campaigns in Enugu. ${ }^{8}$ Although a study in Sabah had found family size as a significant factor associated with vaccinations, it was not the case for this study. ${ }^{11}$ This might be due to the easily accessible facilities as compared to in Sabah where larger family size would mean greater cost needed for mobility and care.

Studies reported in Dambare and Malaysian survey regarding vaccination showed significant relationship between the level of education with immunization. ${ }^{12-13}$ Few other studies supported our finding including a study done in Pilani (India $)^{14}$, Enugu (Nigeria) $)^{8}$ and Sabah(Malaysia) ${ }^{11}$ that there was no significant association between the level of education and level of knowledge and perception towards SIA.

Two factors found to be significantly associated with the level of knowledge towards SIA were household income and occupation. Higher household income group had better knowledge about SIA as also found by various other studies in Pakistan ${ }^{10,15}$, Philippines ${ }^{16}$ and India ${ }^{17}$. Although a Malaysian study found no association between incomplete immunization and parents' occupation $^{12}$ a study in Enugu found that civil servants were more compliant to immunization than traders and housewives ${ }^{8}$ which supported our finding. Respondents from professional group of occupation had better knowledge towards SIA 
compared to non-professionals and housewives. It can be postulated that higher economic group has better access towards information regarding SIA.

This is a pioneer study about the knowledge and perception towards SIA in Peninsular Malaysia and it can be a stepping stone towards future study about SIA done in Malaysia. Awareness, attitude and perception of parents are important factors in ensuring high immunization coverage. The data obtained can be used as a base line in assessing further about the efficacy of SIA from mothers' point of view. However, this is a cross sectional study which does not provide the risk estimations for all the associated factors. Furthermore, limited time for data collection restricted the number of samples.

\section{CONCLUSION}

The findings from this study show that majority of people have poor knowledge and perception and one-third of the respondents have never heard about SIA before. Although SIA is relatively new introduced in the community, society needs to be made aware of these interventions, its services and long-term benefits. This study definitely implies that more intensive health educations may be useful to be incorporated within the program implementation to increase the community understanding and perception towards SIA in the future.

\section{ACKNOWLEDGEMENT}

We would like to thank the Director General of Health, Malaysia for giving permission to publish the findings of this study and to Cheras District Health office for their continuous support throughout this study.

\section{CONFLICTS OF INTEREST}

The authors declare no conflicts of interest

\section{ETHICAL CLEARANCE}

This study was approved by Medical Research Ethical committee, Universiti Kebangsaan Malaysia Medical Centre (FF-2017-247) and National Medical Research and Ethics Committee, Ministry of Health Malaysia (NMRR-17-542-34848IIR).

\section{REFERENCE}

1. WHO 2016. Building trust: The GAP for influenza vaccine approach to improving capacity for better communication.

2. WHO 2013. Global Vaccine Action Plan 2011-2020.

3. Wagner, A. L., Y. Zhang, B. Mukherjee, Y. Ding, E. V. Wells \& M. L. Boulton 2016.
The impact of supplementary immunization activities on the epidemiology of measles in Tianjin, China. Int J Infect Dis 45: 103-8.

4. Onyeka, I. N., A. L. Ilika, F. N. Ilika, D. C. Umeh, R. I. Onyibe, C. J. Okoye, G. Diden \& C. U. Onubogu 2014. Experiences from polio supplementary immunization activities in Anambra State, Nigeria. Niger $J$ Clin Pract 17(6): 808-13.

5. Malhotra, V. 2012. Lessons from Observation of Supplementary Immunization Activity in India. Online $J$ Health Allied Scs. Mangalore, South India(Issue 1).

6. Khetsuriani, N., S. Deshevoi, A. Goel, J. Spika, R. Martin \& N. Emiroglu 2011. Supplementary immunization activities to achieve measles elimination: experience of the European Region. J Infect Dis 204 Suppl 1: S343-52.

7. WHO, W. P. R. 2012. Country ProfileMeasles Elimination Malaysia.

8. Tagbo, B. N., N. D. Uleanya, I. C. Nwokoye, J. C. Eze \& I. B. Omotowo 2012. Mothers' knowledge, perception and practice of childhood immunization in Enugu. Nigerian Journal of Paediatrics 39(3).

9. Mohammad Naeem , M. Z. U. I. K., Muhammad Adil ,Syed Hussain Abbas , Ayasha Khan , Muhammad Usman Khan , Syeda Maria Naz 2012. Coverage And Causes Of Non Immunization In National Immunization Days For Polio; A Consumer And Provider Perspective Study In Peshawar. JPMI Vol.. 26(No 01): 48-54.

10. Aatekah Owais, B. H., Amna R Siddiqui, Ajmal Agha and Anita KM Zaidi 2011 Does improving maternal knowledge of vaccines impact infant immunization rates? A community randomizedcontrolled trial in Karachi,Pakistan. BMC Public Health 2011 11:239.

11. Shamsul Azhar S, N. K., Nazarudin S, Rohaizat H, Azimatun Noor A, Rozita $\mathrm{Ha}$ 2012. Factors Influencing Childhood Immunization Defaulters in Sabah, Malaysia. The International Medical Journal Malaysia Volume 11 Number 1 June 2012.

12. Ahmad, N. A., R. Jahis, L. K. Kuay, R. Jamaluddin \& T. Aris 2017. Primary Immunization among Children in Malaysia: Reasons for Incomplete Vaccination. Journal of Vaccines \& Vaccination 08(03). 
13. Larson, H. J., L. Z. Cooper, J. Eskola, S. L. Katz \& S. Ratzan 2011. Addressing the vaccine confidence gap. The Lancet 378(9790): 526-535.

14. Wise, J. 2011. Final push is needed to tackle last $1 \%$ of polio. BMJ 343.

15. Khowaja, A. R., S. A. Khan, N. Nizam, S. B. Omer \& A. Zaidi 2012. Parental perceptions surrounding polio and selfreported non-participation in polio supplementary immunization activities in Karachi, Pakistan: a mixed methods study. Bull World Health Organ 90(11): 822-30.

16. Bondy, J. N., A. Thind, J. J. Koval \& K. N. Speechley 2009. Identifying the determinants of childhood immunization in the Philippines. Vaccine 27(1): 169-75.
17. Devendra Kumar, A. A., and Sunil Gomber 2010. Immunization Status of Children Admitted to a Tertiary-care Hospital of North India: Reasons for Partial Immunization or Non-immunization. J HEALTH POPUL NUTR 2010 June;28(3):300-304 